\title{
D2-40 antibody immunoreactivity in developing human brain, brain tumors and cultured neural cells
}

\author{
Yasuhiro Nakamura ${ }^{1}$, Yonehiro Kanemura ${ }^{2}$, Tomiko Yamada ${ }^{2,6}$, Yasuo Sugita ${ }^{3}$, \\ Koichi Higaki ${ }^{1}$, Munehiko Yamamoto ${ }^{4}$, Mitsuhiko Takahashi ${ }^{1}$ and Mami Yamasaki ${ }^{2,5}$ \\ ${ }^{1}$ Department of Pathology, St Mary's Hospital, Tsubukuhon-machi, Kurume-shi, Japan; ${ }^{2}$ Institute for Clinical \\ Research, Osaka National Hospital, Hoenzaka, Chuo-ku, Osaka, Japan; ${ }^{3}$ Department of Pathology and \\ Biodefense, Saga Medical School, Nabeshima, Saga, Japan; ${ }^{4}$ Department of Chemistry, Kurume University \\ School of Medicine, Asahi-machi, Kurume, Japan; ${ }^{5}$ Department of Neurosurgery, Osaka National Hospital, \\ Hoenzaka, Chuo-ku, Osaka, Japan and ${ }^{6}$ Institute of Biomedical Research and Innovation, Minatojima \\ Minamimachi, Chuo-ku, Kobe, Hyogo, Japan
}

\begin{abstract}
D2-40 antibody is raised against an oncofetal antigen, the M2A antigen. It has been used as a marker for lymphatic endothelium as well as mesothelioma and cerebellar hemangioblastoma. We demonstrate here that positive D2-40 immunoreactivity was found in the developing cerebrum, particularly in the germinal matrix layer, immature ependyma, choroid plexus and meninges. In the developing cerebellum, positive D2-40 immunoreactivity was found in the external granular layer particularly of the outer portion and the Purkinje cell layer as well as meninges. Some brain tumors such as anaplastic ependymoma, some medulloblastomas, glioblastoma, pineal germinoma, craniopharyngioma, choroid plexus papilloma, choroid plexus carcinoma, and meningioma showed positive immunoreactivity with D2-40. Therefore, D2-40 antibody is considered a useful marker for research on developing brain and diagnosis of brain tumors, differentiation between choroid plexus carcinoma and metastatic carcinoma. In addition, on cultured human neural cells, D2-40 immunoreactivity was found in nestin-positive neural stem/progenitor cells and neuronal lineage cells. As D2-40 antibody recognizes cell surface antigen M2A, it might be a candidate cell surface marker for isolation of human neural stem cells/ neuronal lineage cells in the fluorescence-activated cell sorting technique.
\end{abstract}

Modern Pathology (2006) 19, 974-985. doi:10.1038/modpathol.3800616; published online 28 April 2006

Keywords: D2-40 antibody; immunohistochemistry; germinal matrix layer; brain tumor; neurosphere; cell surface marker

D2-40 is a novel monoclonal antibody against an oncofetal antigen, the M2A antigen, consisting of a 40-kDa sialoglycoprotein with an O-linked simple mucin-type carbohydrate structure. ${ }^{1}$ This antibody was originally considered to be useful for confirming histological diagnosis of seminoma and dysgerminoma. ${ }^{1-3}$ However, a recent study suggested D240 to be a new selective monoclonal immunohistochemical marker of lymphatic endothelium on formalin-fixed and paraffin-embedded tissue specimens. ${ }^{4,5}$ The antibody was applied for evaluation of

Correspondence: Dr Y Nakamura, MD, Department of Pathology, St Mary's Hospital, 422, Tsubukuhon-machi, Kurume-shi 8308543, Japan.

E-mail: naka@st-mary-med.or.jp

Received 3 February 2006; revised 23 March 2006; accepted 31 March 2006; published online 28 April 2006 lymphatic invasion and clinical correlation of various neoplasms such as squamous cell carcinoma in the head and neck region, ${ }^{6}$ of the uterine cervix, ${ }^{7}$ and breast carcinoma. ${ }^{8}$ The positive immunoreactivity with D2-40 antibody was demonstrated in kaposiform hemangioendothelioma suggesting that this tumor could undergo partial differentiation along the lymphatic endothelial lineage. ${ }^{5,9}$ D2-40 antibody is also a sensitive marker of mesothelioma and useful in differential diagnosis of mesothelioma vs adenocarcinoma. ${ }^{10,11}$ One report suggested that the D2-40 antibody specifically recognized human podoplanin and hypothesized podoplanin to be identical to the M2A antigen. ${ }^{12}$ In the central nervous system tissue, vacuolated cells found in cerebellar hemangioblastoma were demonstrated to be strongly positive with D2-40 antibody, and D2-40 is a useful marker to distinguish hemangioblastoma from metastatic clear cell renal cell carcinoma. ${ }^{13}$ 
In the search for immunohistochemical markers of the developing human brain, we raised several novel antibodies such as tubulin beta II as a neural stem cell and neuronal cell lineage marker, ${ }^{14}$ and KIAA0864 protein as a Purkinje cell and its dendrite/axon marker. ${ }^{15}$ Several commercially available antibodies such as nestin, vimentin and GFAP were also evaluated. During the study, we found strong positive immunoreactivity with D2-40 antibody in the germinal matrix layer of the human developing brain. This incidental finding promoted us to study the immunoreactivities with the D2-40 antibody in cultured human neural stem/progenitor cells and their derivatives as well as the developing human cerebrum, cerebellum and some brain tumors.

\section{Materials and methods}

\section{Materials}

Cerebrum samples for immunohistochemical study were obtained from spontaneous abortion or at autopsy from 34 cases ranging from 6 gestational weeks to 59 years (two cases each at 6 and 19 gestational weeks, one case each at $7,8,9,10,11,14$, 15 and 18 gestational weeks, nine cases at 20-29 gestational weeks, five cases at 30-40 gestational weeks, three cases at 1-6 months of age, one at 1 year, one at 5 years and three at 30-59 years). Cerebellum samples were from 25 cases out of the 34 cases ranging from 8 gestational weeks to 59 years (one case each at 8, 9, 10, 14, 15, 18 and 19 gestational weeks, five cases at 20-29 gestational weeks, five cases at 30-40 gestational weeks, three cases at 1-6 months of age, one at 1 year, one at 5 years and three at 30-59 years). Most samples (22 out of 34 cases) were obtained at autopsy within $12 \mathrm{~h}$ after death. Brain tumor samples were obtained from biopsy and resected materials of 34 cases (four ependymal tumors, four medulloblastomas, three astrocytomas grade 2, five glioblastomas, three cases of pineal germinoma, six craniopharyngiomas, four choroid plexus tumors and five meningiomas). Six cases of papillary carcinoma in other tissues (thyroid gland, breast, pancreas, ovary and colon) were also prepared. Ten percent buffered formaldehyde-fixed and paraffin-embedded sections from all samples were prepared for immunohistochemistry. Human fetal forebrain tissues (between 7 and 10 gestational weeks) were collected from the Osaka National Hospital for the culture of neural stem/ progenitor cells. This study was carried out in accordance with the principles of the Helsinki Declaration and was approved by the Ethical Committee of each institution.

\section{Light Microscopic Immunohistochemical Study}

Paraffin-embedded specimens were used for light-microscopic immunohistochemistry. Light- microscopic immunohistochemical staining was performed with a commercially available kit (Histofine HER 2 kit, Nichirei, Tokyo, Japan) colored with diaminobenzidine according to the manufacturer's instructions. In this study, commercially available mouse monoclonal antibodies D2-40 from two companies (Nichirei, Tokyo, Japan and Signet, Dedham, MA, USA) were used. Other commercially available antibodies against nestin (rabbit polyclonal, Chemicon, Temecula, CA, USA), vimentin (mouse monoclonal, DAKO, Carpinteria, CA, USA) and GFAP (mouse monoclonal, DAKO) were used as markers of neural stem cell/progenitor cell and glial lineage cells. Our raised antibody HFB-16 against KIAA0864 protein (as a marker for cerebellar Purkinje cell and its dendrite/axon) ${ }^{15}$ was also applied. The slides were pretreated (antigen rescue) by microwaving them for $15 \mathrm{~min}$ in $10 \mathrm{mM}$ citrate buffer at $\mathrm{pH} 6.0$ or incubating them in a hot water bath $\left(95^{\circ} \mathrm{C}, 40 \mathrm{~min}\right)$ in the same buffer. The dilutions of primary antibodies were 1:50 (D2-40, Signet), 1:100 (D2-40, Nichirei), 1:200 (nestin, vimentin and GFAP) and 1:1000 (HFB-16). For controls, the primary antibodies were omitted or primary antibodies preadsorbed with excess brain homogenate or normal sera were used. Hematoxylin and eosin (HE) staining was also performed.

The percentage of positive immunoreactivity was classified into four groups: intense, $>50 \%$ of cells labeled; moderate, $5-50 \%$ of cells labeled; weak, $<5 \%$ of tumor cells labeled; and negative, no staining.

\section{Human Neural Stem/Progenitor Cells Culture and Differentiation}

Human fetal forebrain tissues (between 7 and 10 gestational weeks) were collected from the Osaka National Hospital. Approval was obtained from both the Osaka National Hospital and the Tissue Engineering Research Center local ethic committees. Samples were mechanically dissected in Dulbecco's-modified Eagle's Medium (DMEM)/Ham's F-12 (1:1). After dissection, tissue samples were incubated in $0.05 \%$ trypsin and $0.5 \mathrm{mM}$ EDTA (Invitrogen, Carlsbad, CA, USA) for $20 \mathrm{~min}$ at $37^{\circ} \mathrm{C}$. Enzymatic activity of trypsin was inhibited by trypsin inhibitor (Roche Diagnostics Corporation, Indianapolis, IN, USA). Cell suspensions were grown using the neurosphere method ${ }^{16}$ in a defined DMEM/F-12 (1:1)-based growth medium supplemented with human recombinant (hr-) epidermal growth factor $(20 \mathrm{ng} / \mathrm{ml}$, Invitrogen), hr-fibroblast growth factor $2(20 \mathrm{ng} / \mathrm{ml}$, PeproTech Inc, Rocky Hill, NJ, USA), hr-LIF(10ng/ml, Chemicon), heparin ( $5 \mu \mathrm{g} / \mathrm{ml}$, Sigma, St Louis, MS, USA), B27 supplement (Invitrogen), $15 \mathrm{mM}$ HEPES as previously reported. ${ }^{14,16,17}$ To induce differentiation, neurospheres were plated on poly-ornithine-coated glass coverslips and cultured in the medium with all 
three growth factors withdrawn and supplemented with 1\% FBS. Cells were cultured for 14 days before fixation for immunocytochemistry.

\section{Immunocytochemical Analysis}

The neurospheres were fixed in phosphate-buffered saline (PBS) containing $4 \%$ paraformaldehyde (PHA) for $20 \mathrm{~min}$ at room temperature. After fixation, the neurospheres were dipped in $30 \%$ sucrose in PBS for $30 \mathrm{~min}$ at room temperature, embedded in OCT-compound (Sakura Finetechnical, Tokyo, Japan) and sectioned at $12 \mu \mathrm{m}$ on a cryotome. The differentiated cells were also fixed in PBS containing $4 \%$ PHA for $20 \mathrm{~min}$ at room temperature. Frozen sections of neurospheres were incubated with two primary antibodies to nestin (rabbit polyclonal; $1: 500)^{14}$ and $\mathrm{D} 2-40$ in $\mathrm{PBS} / 0.1 \%$ Triton-X/10\% normal goat serum at $4{ }^{\circ} \mathrm{C}$ overnight. Nuclei were stained with TO-PRO- $3^{\circledR}$ (Molecular Probes Inc., Eugene, OR, USA). Coverslips were incubated with another set of two primary antibodies against D2-40, the polysialic acid-neural cell adhesion molecules (PSA-NCAM) (mouse IgM; kindly gifted by $\mathrm{Dr}$ Seki, Department of Anatomy, Juntendo University School of Medicine, 1:500), ${ }^{18}$ or GFAP (rabbit poly, Sigma, 1:80) with TO-PRO- $3^{\circledR}$ in the same reaction conditions. After three washes, neurosphere sections and coverslips were incubated with adequate secondary antibodies (Alexa Fluor ${ }^{\circledR}$ 488 goat anti-mouse IgG, Alexa Fluor ${ }^{\circledR} 568$ goat anti-rabbit or mouse IgG, and Alexa Fluor ${ }^{\circledR} 488$ goat anti-mouse IgM, Molecular Probes Inc.) at room temperature for $1 \mathrm{~h}$. Sections and coverslips were examined using laser-scanning microscope (Carl Zeiss LSM510).

\section{Results}

\section{D2-40 Immunoreactivity in Developing Human Cerebrum}

Both commercially available D2-40 antibodies from Nichirei and Signet revealed the same results, therefore each antibody is applicable and obtained reproducible results.

In the 6 gestational weeks cerebrum, the positive immunoreactivity with D2-40 was found throughout the entire zone of the cerebrum in a fibrous and reticular pattern. Compared with immunoreactivities with nestin, which were mainly positive in the radial fibers, D2-40 immunopositivity was found more diffusely, including on the surface of radial fibers and migrating neuroblasts (Figure 1). In 8-14 gestational weeks, the range of positive immunoreactivity became decreased and restricted to the deep white matter and the germinal matrix layer. In 15 gestational weeks, intense positive immuno-
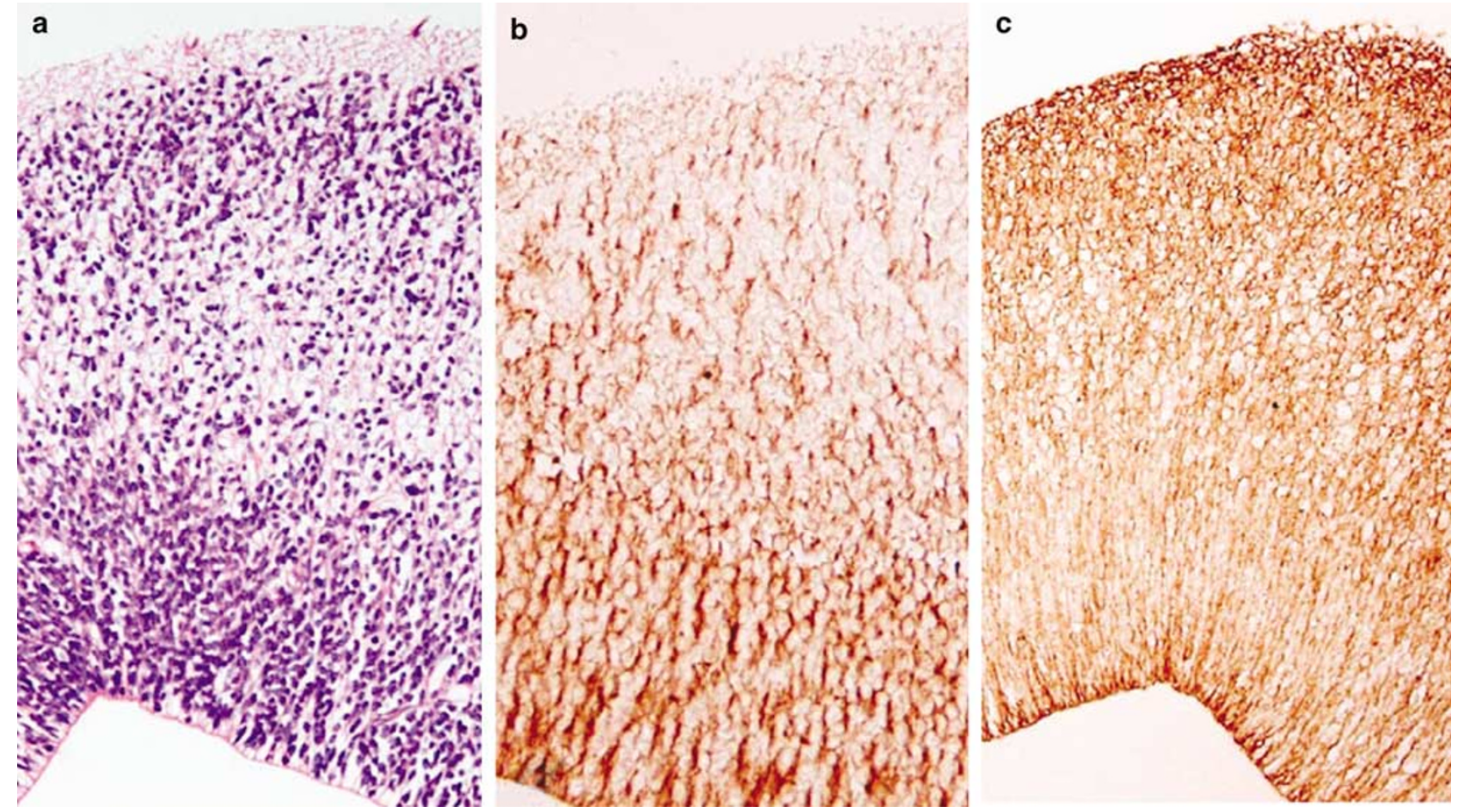

Figure 1 Six gestational weeks cerebrum. (a) HE staining. (b) Nestin. (c) D2-40. Positive immunoreactivity with D2-40 was found throughout the entire zone of the cerebrum in a fibrous and reticular pattern. Compared with immunoreactivity with nestin, which was mainly positive in the radial fibers, D2-40 immunopositivity was found more diffusely, including the surface of radial fibers and migrating neuroblasts. (b and $\mathbf{c}$ ) Without counterstaining. 

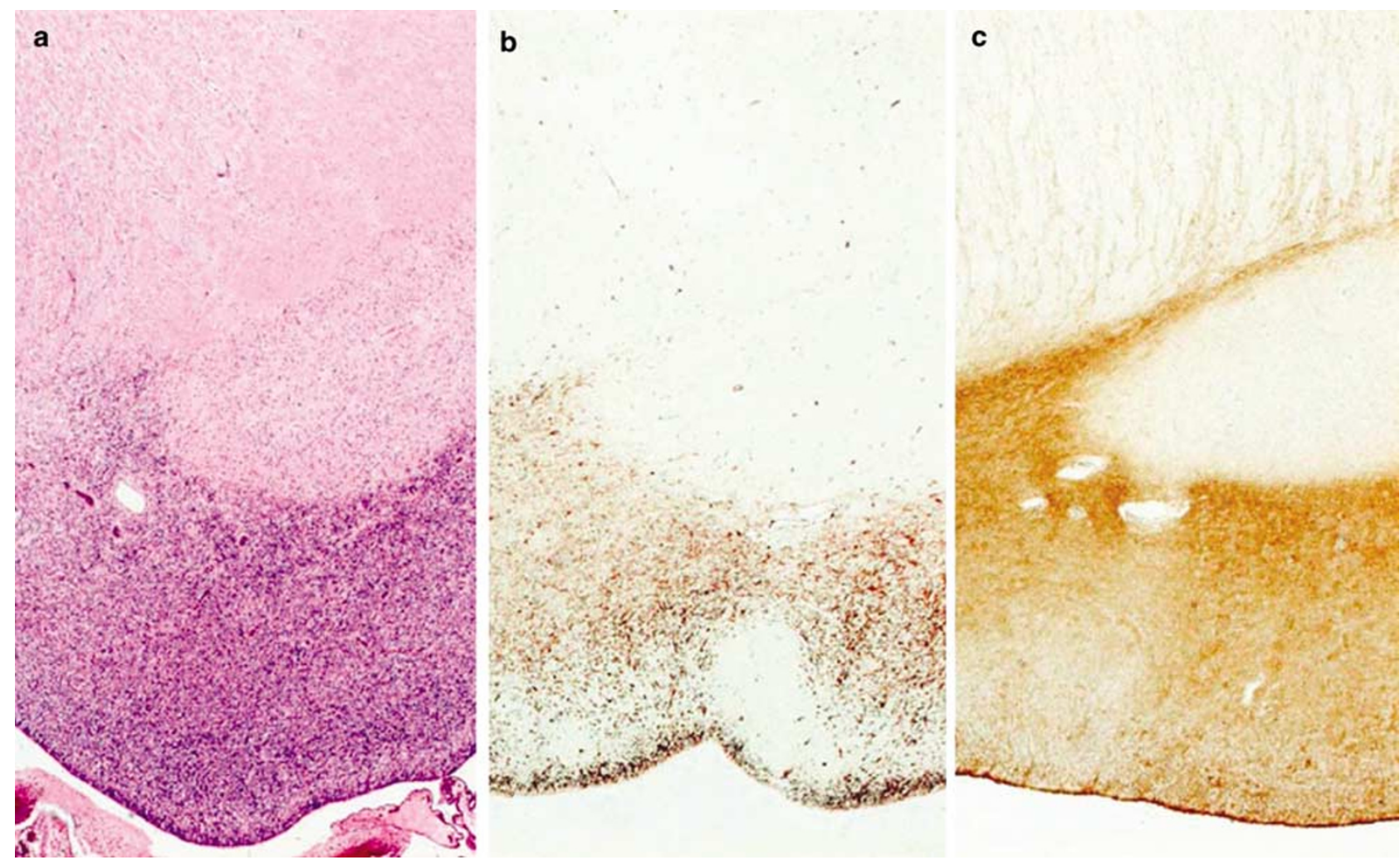

Figure 2 Twenty-eight gestational weeks cerebrum. (a) HE staining. (b) Vimentin. (c) D2-40. The localized germinal matrix layer was intensely immunopositive with D2-40 as well as vimentin. Compared with vimentin immunoreactivity, D2-40 positivity was more diffusely distributed in the matrix as well as cellular components in the germinal matrix layer. (b and c) Without counterstaining.

reactivity was seen in and around the germinal matrix layer, ependymal cells and leptmeninges. During 18-29 gestational weeks, the germinal matrix layer was localized and became prominent over the caudate head, over the caudate-thalamic groove, over the caudate tail along the inferior horn, and along the trigone of the lateral ventricle. The localized germinal matrix layer was intensely immunopositive with D2-40 as well as vimentin (Figure 2). Compared with vimentin immunoreactivity, D2-40 positivity was more diffusely distributed in the matrix as well as cellular component in the germinal matrix layer. Vimentin and GFAP positivity was found in glioblasts and mature astrocytes; however, D2-40 positivity was seen only in glioblasts and not in mature astrocytes. After 30 gestational weeks, the germinal matrix layer became regressed and cellular components in the germinal matrix layer decreased rapidly in number. However, D2-40 immunoreactivity remained as intense in ependymal cells and as moderately intense as in the germinal matrix layer (Figure 3a). Compared with GFAP and vimentin, which was positive in astrocytes found in the deep white matter, D2-40 immunoreactivity was only weakly seen in deep white matter. In adult brains, weak-moderate immunoreactivity with D2-40 was found in the ependymal and subependymal region (Figure $3 \mathrm{~b}$ ). The apical surface of epithelial cells in the choroid plexus was intensely stained with D2-40 antibody throughout 8 gestational weeks to adult (Figure 4a) Moderate positive D2-40 reactivity was found in leptomeninges throughout 9 gestational weeks to adult (Figure 4b) Mature neurons and oligodendrocytes were negative for D2-40.

\section{D2-40 Immunoreactivity in Developing Human Cerebellum}

In the 8-15 gestational weeks cerebellum, there was negative or weak immunoreactivity with D2-40. In the 18 gestational weeks cerebellum, intense positive immunostaining appeared in the external granular layer and moderate positive immunostaining in the molecular and Purkinje layer as a fibrillar and/or reticular pattern, while positive immunostaining with HFB 16 appeared in 3-5 layers as short processes of Purkinje cells. In 20-29 gestational weeks, leptomeninges and the outer portion of the external granular layer showed intensely positive immunoreactivity with D2-40. The inner part of the external granular layer and the molecular layer were moderately positive as a fibrillar pattern. The surface of the Purkinje cell was moderate-intense immunoreactive. During 30-40 gestational weeks, positive immunoreactivity with $\mathrm{D} 2-40$ became intense around Purkinje cells as well as the outer 

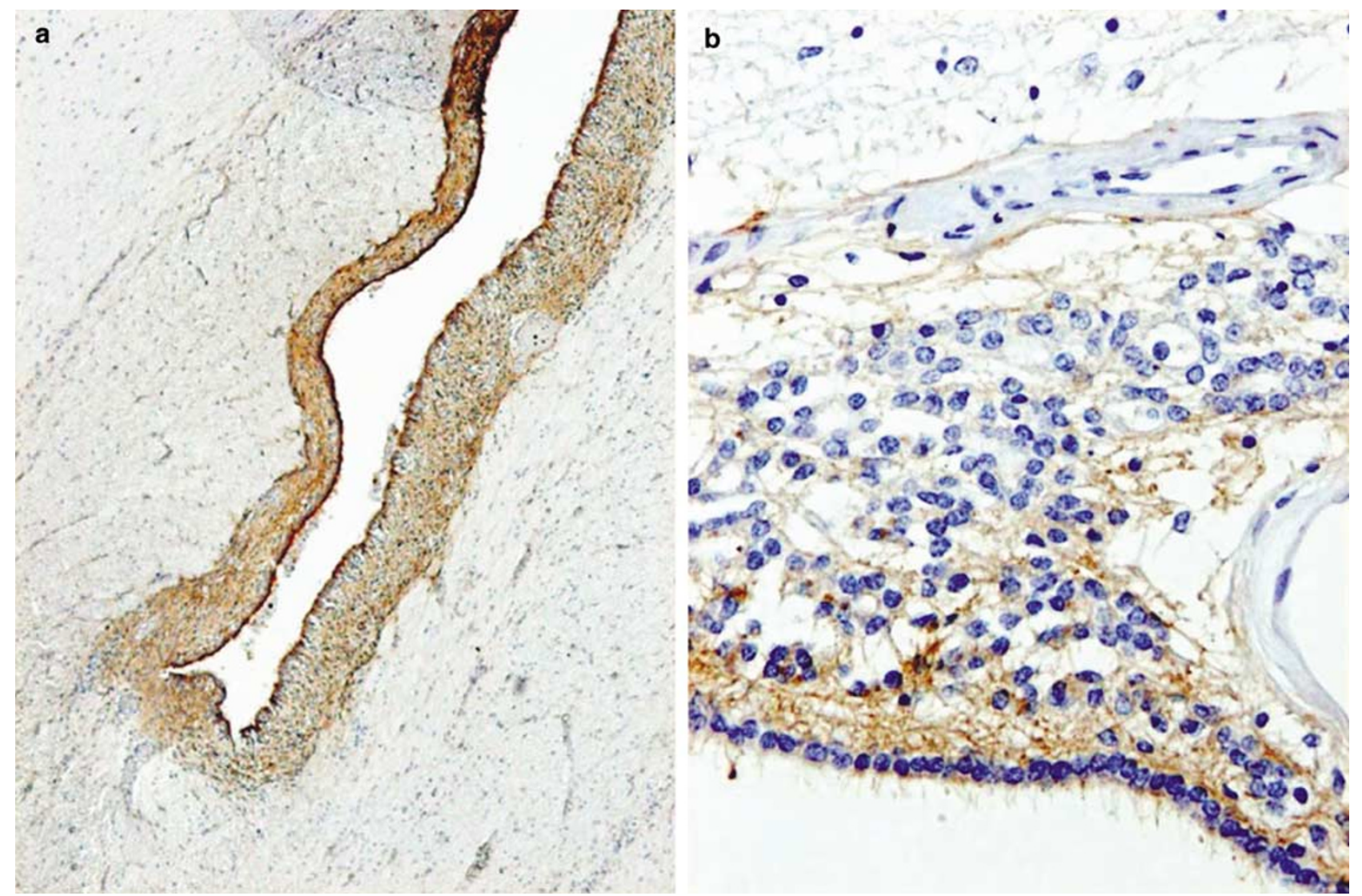

Figure 3 (a) Thirty-five gestational weeks cerebrum. D2-40. The germinal matrix layer became regressed and cellular components in the germinal matrix layer were decreased in number. However, D2-40 immunoreactivity still remained as intense as in ependymal cells and as moderately intense as in the germinal matrix layer. With counterstaining. (b) 59-year-old cerebrum. D2-40. In adult brains, weakmoderate immunoreactivity with D2-40 was found in the ependymal and subependymal region. With counterstaining.

portion of the external granular layer. Compared to immunoreactivity with HFB 16, which was intensely positive in the cytoplasm of Purkinje cells and their dendrites (Figure 5b), D2-40 immunoreactivity was seen on the surface of and around Purkinje cells and their dendrites not in the cytoplasm (Figure 5c). After birth (up to 1 year of age), the distribution of D2-40 immunoreactivity remained around fully developed dendrites and the immunoreactivity along the nerve fibers appeared to be intensified. Around 1 year of age, the external granular layer disappeared and intense immunoreactivity in the external granular layer also disappeared; however, moderate immunoreactivity in leptomeninges remained. In the adult cerebellum, D2-40 moderate immunoreactivity was found along the mature dendrites of the Purkinje cells in the molecular layer, on the surface of Purkinje cells, along nerve fibers in the white matter and leptomeninges. The internal granular layer showed negative staining throughout the fetal, infant and adult stages except for the neural fibers from Purkinje cells.

A summary of D2-40 immunohistochemistry in the different stages of developing cerebrum and cerebellum is shown in Table 1.

\section{D2-40 Immunoreactivity in Brain Tumors}

One case of ependymoma showed weak immunoreactivity and another case showed intense immunoreactivity with D2-40. Both cases of anaplastic ependymoma showed intense immunoreactivity with D2-40 (Figure 6a). Out of four cases of medulloblastoma, two cases revealed weak to moderate immunoreactivity in some differentiated cell components (Figure 6b). Two other cases were almost completely negatively stained. All three astrocytomas showed negative to weak immunopositivity with D2-40. In two out of five cases of glioblastoma, weak immunoreactivity was seen. Three cases showed moderate immunoreactivity (Figure 6c). All three cases of pineal germinoma revealed intense immunoreactivity with D2-40 on the surface of tumor cells (Figure 7a). In all six cases of craniopharyngioma, intense immunoreactivity was found in the epithelial components of this tumor, while negative or weak positivity in the stroma was observed (Figure 7b). All three cases of choroid plexus papilloma showed intense positive immunoreactivity with D2-40 along the apical surface of the tumor epithelium. A single case of choroid plexus carcinoma showed moderate 

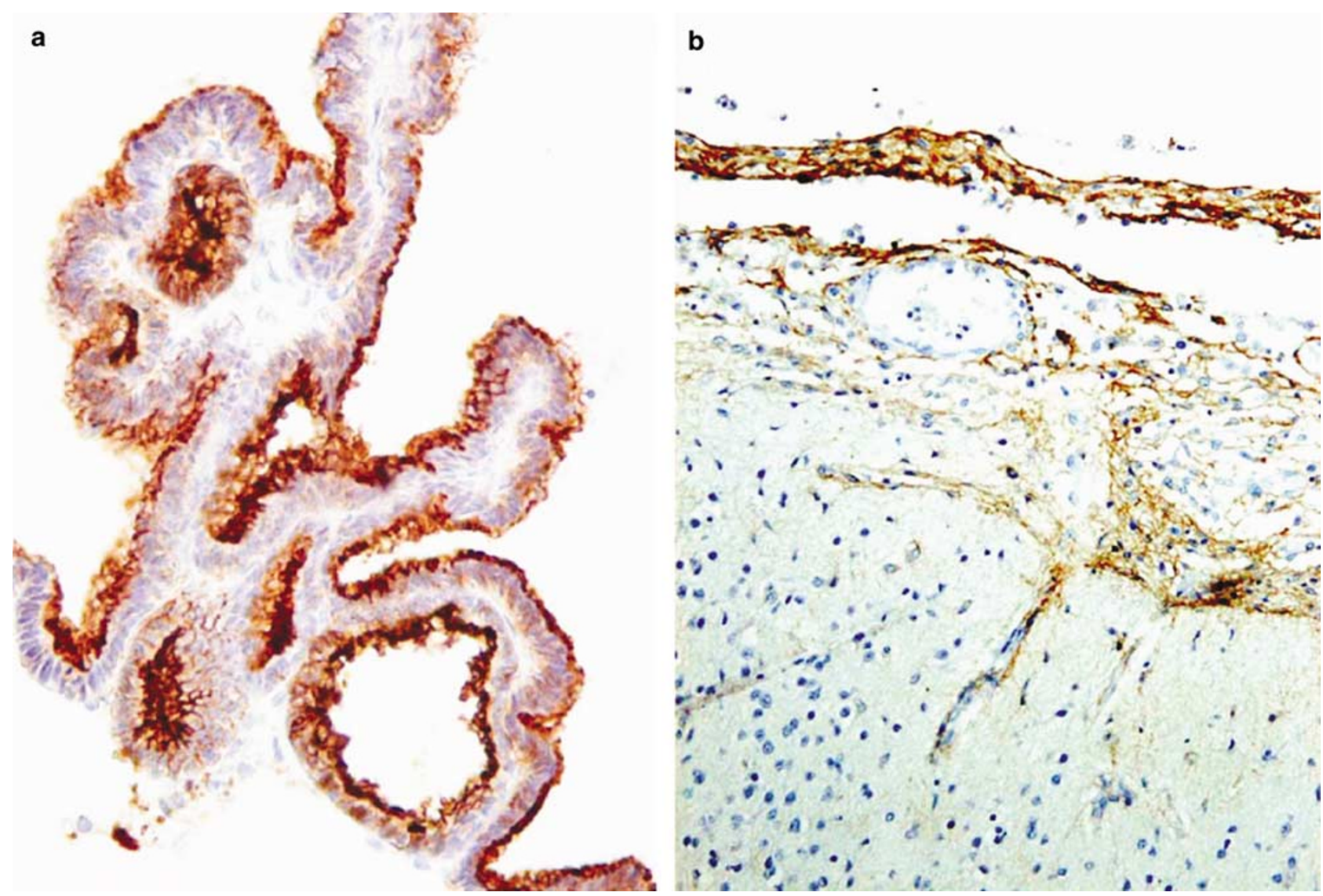

Figure 4 (a) Nineteen gestational weeks choroid plexus. (b) 35 gestational weeks meninges. The apical surface of epithelial cells in the choroid plexus was intensely stained with D2-40 antibody. Moderate positive D2-40 reactivity was found in leptomeninges. With counterstaining.

positive immunoreactivity (Figure 7c), although all six papillary carcinomas in other organs were negative for D2-40. Three out of five cases of meningioma showed intense immunoreactivity with D2-40 (Figure 7d). Two other cases showed moderate immunoreactivity.

A summary of the immunoreactivity in brain tumors is shown in Table 2.

\section{D2-40 Immunoreactivity on Human Cultured Neural Cells}

The majority of cells within neurospheres were positively immunostained with D2-40 antibody on the surface of neural stem cells as well as nestin antibody in the cytoplasm of neural stem cells (Figure 8). After induction of differentiation, the distribution of immunoreactivity of D2-40 was similar to that of PSA-NCAM, indicating expression in the neuronal differentiated lineage (Figure 9a). Only a small number of D2-40-positive cells seemed to share the positive immunoreactivity to GFAP (Figure 9b).

\section{Discussion}

This is the first report that demonstrated intense immunoreactivity in the germinal matrix layer of human developing cerebrum and cultured neural cells. In the developing human cerebrum, neural stem/progenitor cells proliferate in the germinal matrix layer, thereafter a series of neuronal migrations occur during which postmitotic neuroblasts leave the germinal matrix layer and move to the cortical plate along radial guidance fibers. ${ }^{19}$ Several immunohistochemical markers for the germinal matrix layer cells and radial guidance fibers have been reported. Nestin is the product of a newly found gene encoding a protein classified as a distinct sixth class of intermediate filaments. ${ }^{20}$ It has been reported to express in the germinal matrix layer cells and radial fibers during the neuronal migration and be gradually replaced by vimentin. ${ }^{21,22}$

D2-40 immunoreactivity was intensely found in the germinal matrix layer cells and radial fibers in 6 gestational weeks and thereafter it became restricted in and around the germinal matrix layer gradually. In the germinal matrix layer, the cell surface of ependymal cells, neural stem/progenitor cells and glioblasts were intensely immunoreactive with D2-40 during 8-30 gestational weeks. After regression of the germinal matrix layer, D2-40 immunoreactivity remained in ependymal cells and matrices of the periventricular region. D2-40 immunoreactivity was found in glioblasts temporally but not in 


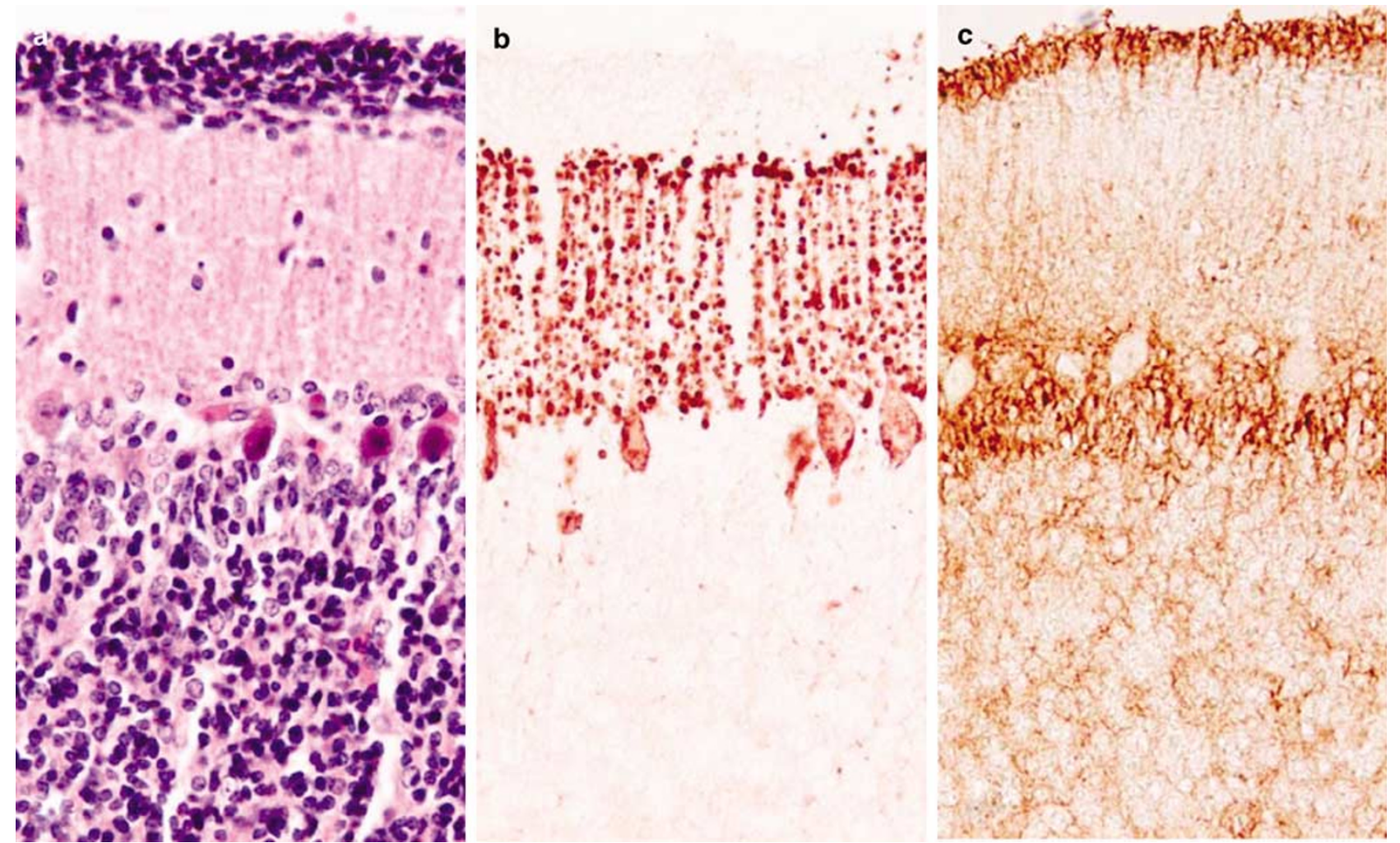

Figure 5 Thirty-eight gestational weeks cerebellum. (a) HE staining. (b) HFB-16. (c) D2-40. Positive immunoreactivity with D2-40 became intense around Purkinje cells as well as the outer portion of the external granular layer. Compared to immunoreactivity with HFB-16, which was intensely positive in the cytoplasm of Purkinje cells and their dendrites, D2-40 immunoreactivity was seen on the surface of and around Purkinje cells and their dendrites but not in the cytoplasm. (b and $\mathbf{c}$ ) Without counterstaining.

Table 1 D2-40 immunohistochemistry in the different stages of developing brain

\begin{tabular}{|c|c|c|}
\hline & Cerebrum & Cerebellum \\
\hline $6 \mathrm{GW}$ & +++ (entire zone) & No data available \\
\hline 8-15 GW & $+++($ GML and deep WM) & - or + \\
\hline $18 \mathrm{GW}$ & $+++(\mathrm{GML})$ & $\begin{array}{l}+++(\text { EGL }) \\
++(\text { MOL and PUR) }\end{array}$ \\
\hline 20-29 GW & $+++(\mathrm{GML})$ & $\begin{array}{l}+++(\text { outer EGL) } \\
++ \text { to }+++(\text { PUR }) \\
++(\text { inner EGL and MOL) }\end{array}$ \\
\hline $30-40 \mathrm{GW}$ & ++ (remained GML) & +++ (outer EGL and PUR) \\
\hline$<1 \mathrm{y}$ & + to $++($ EP and SEP $)$ & $\begin{array}{l}++(\text { PUR and MOL }) \\
+(\text { EGL })\end{array}$ \\
\hline $1 \mathrm{y}$ & + to ++ (EP and SEP) & $\begin{array}{l}++(\text { PUR, MOL and WM) } \\
-(\text { EGL disappeared) }\end{array}$ \\
\hline Child-adult & + to ++ (EP and SEP) & ++ (PUR, MOL and WM) \\
\hline Throughout $8-9 \mathrm{GW}$ to adult & ++ to +- & d plexus) \\
\hline
\end{tabular}

GW: gestational weeks; y: year old; GML: germinal matrix layer; WM: white matter; EP and SEP: ependymal and subependymal; EGL: external granular layer; MOL: molecular layer; PUR: Purkinje cell layer; -: negative, no staining; +: weak, $<5 \%$ of cells in the laeyr labeled; ++: moderate, $5-50 \%$ of cells labeled; +++: intense, $>50 \%$ of cells labeled.

mature astrocytes or oligodendrocytes. It is hypothesized that D2-40 is a novel marker for the germinal matrix layer cells (neural stem/progenitor cells) and their derivative cells such as ependymal cells and glioblasts. The presence of podoplanin in the choroid plexus, ependyma and meninges was reported and the authors of the report hypothesized that podoplanin is identical to the $\mathrm{M} 2 \mathrm{~A}$ antigen, which was recognized by the D2-40 antibody. ${ }^{12}$ The results of our study (D2-40 positivity in choroid plexus, ependyma and meninges) support their hypothesis.

Intense D2-40 staining on the cell surface of Purkinje cells and their dendritic processes was 

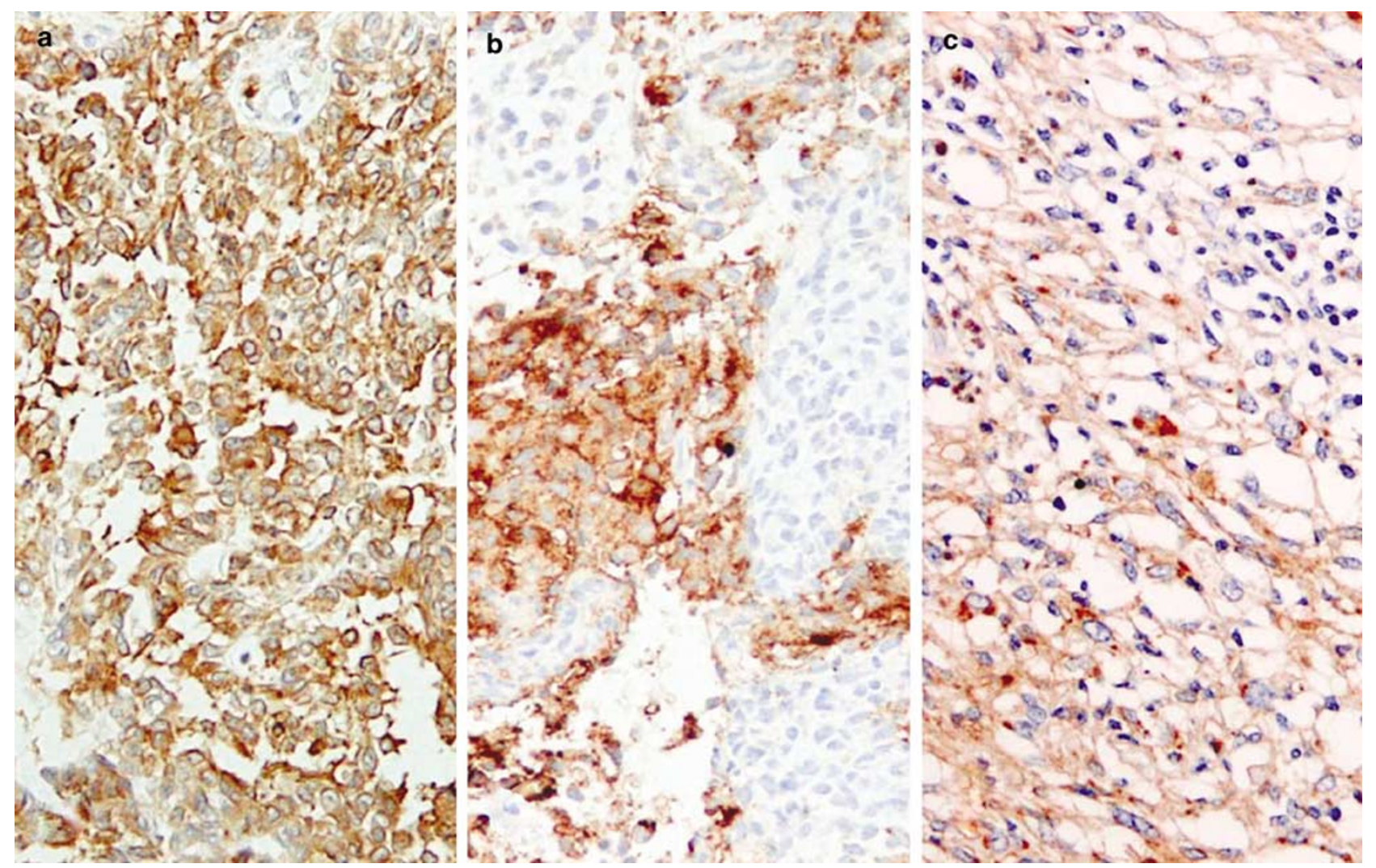

Figure 6 (a) Anaplastic ependymoma showing intense immunoreactivity with D2-40. (b) Medulloblastoma showing moderate immunoreactivity mainly in some differentiated cell components. (c) Glioblastoma showing moderate immunoreactivity. With counterstaining.

described in the non-neoplastic cerebellar cortex found incidentally during the search for D2-40 immunoreactivity in cerebellar hemangioblastoma. ${ }^{13}$ Our study confirmed the observation of D240 immunoreactivity on the cell surface of Purkinje cells and their dendritic processes ${ }^{13}$ and first described that intense D2-40 staining was seen in the outer part of the external granular layer. Monoclonal antibodies against MAP2, IP3R1 and KIAA0864 protein have been used to detect Purkinje cells with immunohistochemistry in formalin-fixed and paraffin-embedded brain samples from normal development ${ }^{15,23,24}$ and diseased brains. ${ }^{25,26}$ This study has shown that while HFB-16 (antibody against KIAA0864 protein) immunoreactivity was found only in the cytoplasm of Purkinje cell and its dendrite/axon, D2-40 immunoreactivity was seen on the surface of and around Purkinje cell and its dendrite/axon as well as the external granular layer. In the human cerebellum, neuroblasts migrate radially outward from the germinal matrix layer in the wall of the fourth ventricle and settle in the deep cerebellar nuclei and the Purkinje cell layer between 9 and 13 gestational weeks. ${ }^{27}$ The germinal matrix layer disappears at birth. Another pathway begins at 11 and 13 gestational weeks when the germinative cells migrate tangentially from the germinal matrix layer over the cerebellar surface, forming the external granular layer. Neuroblasts generated from the external granular layer begin to migrate inward around 16 gestational weeks and form the basket and stellate cells of the molecular layer and finally the internal granular layer. Thus, Purkinje cells and the external granular layer/internal granular layer are differently developed; however, D2-40 antibody recognized both Purkinje cells and external granular layer cells, but not external granular layer cells. In the cerebrum, no mature neurons showed positive immunoreactivity with D2-40. It is uncertain why only Purkinje cell neurons showed positive immunoreactivity with D2-40 along with external granular layer cells.

Both in ependymal tumors and astroglial tumors, less differentiated tumors revealed more positive immunoreactivities with D2-40. Medulloblastoma, the most primitive tumor in this study and considered to be of the external granular layer origin, showed positive immunoreactivity in part of some differentiated cell component. Several reports showed higher expression of selective makers of neural stem/progenitor cells, like nestin or musashi1, in malignant gliomas suggesting the biological analogy between neural stem/progenitor cells and glioma cells and the usefulness of these markers for clinical diagnosis of malignant gliomas. ${ }^{21,28}$ Present findings suggest D2-40 may be a useful marker for characterizing tumor properties and for examining in situ the analogy between normal neural stem/ 

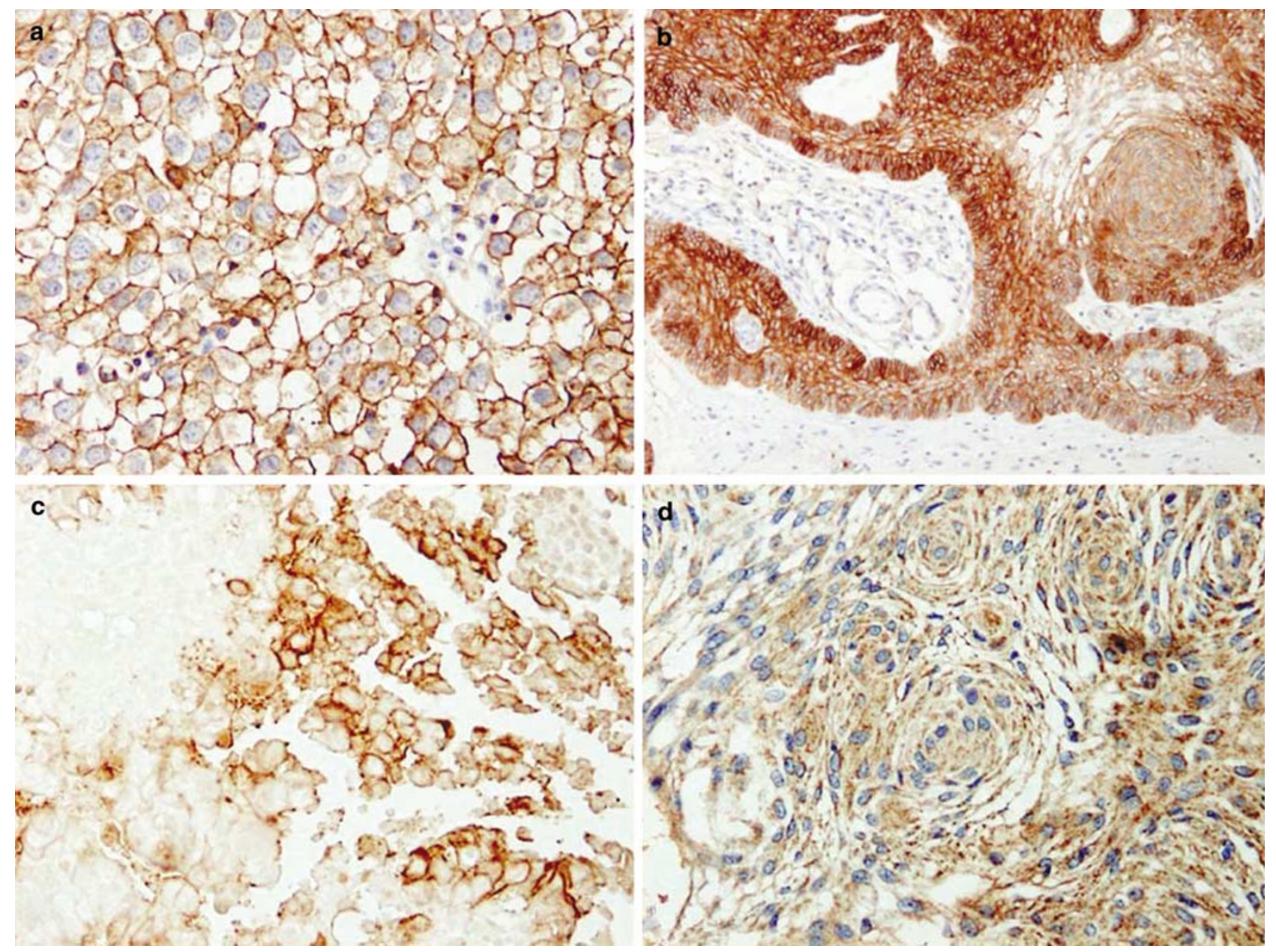

Figure 7 (a) Pineal germinoma showed intense immunoreactivity with D2-40 on the surface of tumor cells. (b) Craniopharyngioma: intense immunoreactivity was found in epithelial components of this tumor, while negative or weak positivity was seen in the stroma. (c) Choroid plexus carcinoma showed moderate positive immunoreactivity. (d) Meningioma showed intense immunoreactivity with D2-40. (a, b and $\mathbf{d}$ ) with counterstaining. (c) Without counterstaining.

progenitor cells and brain tumor cells. The result that pineal germinoma was intensely positively stained with D2-40 is reasonable because of positivity in seminoma and dysgerminoma. ${ }^{1-3}$ Intense immunoreactivity in the epithelial components of craniopharyngioma was expected because the positive staining in basal keratinocytes of the normal skin and skin cancer was reported. ${ }^{12}$ Intense immunoreactivity in choroid plexus papilloma was also predictable because the presence of positive staining in normal choroid plexus was determined in this study and a previous study. ${ }^{12,29}$ Moderate immunopositivity in choroid plexus carcinoma is very useful in differentiating from metastatic papillary carcinoma. All six cases of papillary carcinoma in other organs such as thyroid gland, breast, pancreas, ovary and colon showed completely negative staining with D2-40. The diagnosis of choroid plexus carcinoma is usually very difficult; therefore, the demonstration of the positive immunoreactivity with D2-40 could be a strong tool for differential diagnosis of choroid plexus carcinoma and metastatic papillary carcinoma. Normal leptomeniges in developing and adult brain and meningioma showed moderate-intense immunopositivity with D2-40.

From cultured neural cells study, intense D2-40 immunoreactivity was confirmed in nestin-positive neural stem/progenitor cells. Moreover, D2-40-positive immunoreactivity was found in neuronal progenitor cells and developing neuron, that express PSA-NCAM. ${ }^{18}$ These findings indicate that human neural stem/progenitor cells and/or neuronal lineage cells express D2-40 antigen. In developing human brain tissues and differentiation-induced neural stem/progenitor cells, some cells shared positive immunoreactivity with both GFAP and D2-40 suggesting that D2-40 antigen is expressed in progenitor cells of glial differentiation (glioblasts).

A recent study has demonstrated that neural stem cells can differentiate into endothelial lineage. ${ }^{30}$ And more, it is reported nestin-positive human neural stem/progenitor cells highly express ATPbinding cassette (ABC) transporters, like ABCB1 
Table 2 D2-40 immunoreactivity in brain tumors

\begin{tabular}{|c|c|c|c|c|}
\hline No & Age & Sex & Histology & D2-40 immunoreactivity \\
\hline 1 & $1 \mathrm{y}$ & M & Ependymoma & + \\
\hline 2 & $2 \mathrm{y}$ & $\mathrm{M}$ & Ependymoma & +++ \\
\hline 3 & $1 \mathrm{y}$ & $\mathrm{M}$ & Anaplastic ependymoma & +++ \\
\hline 4 & $2 \mathrm{y}$ & $\mathrm{M}$ & Anaplastic ependymoma & +++ \\
\hline 5 & $1 \mathrm{y}$ & $\mathrm{F}$ & Medulloblastoma with glial diff & + \\
\hline 6 & $7 \mathrm{y}$ & $\mathrm{M}$ & Medulloblastoma with neuroglial diff & ++ \\
\hline 7 & $2 \mathrm{y}$ & $\mathrm{M}$ & Medulloblastoma ND & - \\
\hline 8 & $4 \mathrm{y}$ & $\mathrm{F}$ & Medulloblastoma ND & - \\
\hline 9 & $3 \mathrm{y}$ & $\mathrm{F}$ & Astrocytoma G2 & - \\
\hline 10 & $18 \mathrm{y}$ & $\mathrm{M}$ & Astrocytoma G2 & - \\
\hline 11 & $35 \mathrm{y}$ & $\mathrm{F}$ & Astrocytoma G2 & + \\
\hline 12 & $44 \mathrm{y}$ & $\mathrm{F}$ & Glioblastoma & + \\
\hline 13 & $73 \mathrm{y}$ & $\mathrm{F}$ & Glioblastoma & + \\
\hline 14 & $14 \mathrm{y}$ & $\mathrm{M}$ & Glioblastoma & ++ \\
\hline 15 & $62 \mathrm{y}$ & $\mathrm{M}$ & Glioblastoma & ++ \\
\hline 16 & $71 \mathrm{y}$ & $\mathrm{M}$ & Glioblastoma & ++ \\
\hline 17 & $9 \mathrm{y}$ & $\mathrm{M}$ & Pineal germinoma & +++ \\
\hline 18 & $22 \mathrm{y}$ & $\mathrm{M}$ & Pineal germinoma & +++ \\
\hline 19 & $25 \mathrm{y}$ & $\mathrm{F}$ & Pineal germinoma & +++ \\
\hline 20 & 11 mon & $\mathrm{M}$ & Craniopharyngioma & +++ (epithel)-(stroma) \\
\hline 21 & $4 \mathrm{y}$ & $\mathrm{F}$ & Craniopharyngioma & +++ (epithel)-(stroma) \\
\hline 22 & $8 \mathrm{y}$ & $\mathrm{F}$ & Craniopharyngioma & +++ (epithel)+(stroma) \\
\hline 23 & $8 \mathrm{y}$ & $\mathrm{M}$ & Craniopharyngioma & +++ (epithel) - (stroma) \\
\hline 24 & $12 \mathrm{y}$ & $\mathrm{M}$ & Craniopharyngioma & +++ (epithel)+(stroma) \\
\hline 25 & $25 \mathrm{y}$ & $\mathrm{M}$ & Craniopharyngioma & +++ (epithel)-(stroma) \\
\hline 26 & $10 \mathrm{y}$ & $\mathrm{M}$ & Choroid plexus papilloma & +++ (apical surface) \\
\hline 27 & $10 \mathrm{y}$ & $\mathrm{M}$ & Choroid plexus papilloma & +++ (apical surface) \\
\hline 28 & $24 \mathrm{y}$ & $\mathrm{M}$ & Choroid plexus papilloma & +++ (apical surface) \\
\hline 29 & $54 \mathrm{y}$ & $\mathrm{M}$ & Choroid plexus carcinoma & ++ \\
\hline 30 & 1 mon & $\mathrm{F}$ & Fibroblastic meningioma & ++ \\
\hline 31 & $42 \mathrm{y}$ & $\mathrm{F}$ & Meningotheliomatous meningioma & +++ \\
\hline 32 & $50 \mathrm{y}$ & $\mathrm{F}$ & Transitional meningioma & ++ \\
\hline 33 & $56 \mathrm{y}$ & $\mathrm{F}$ & Meningotheliomatous meningioma & +++ \\
\hline 34 & $66 \mathrm{y}$ & $\mathrm{F}$ & Meningotheliomatous meningioma & +++ \\
\hline
\end{tabular}

y: years old; mon: months old; F: female; M: male; diff: differentiation; ND: not differentiated; G: grade; -: negative, no staining; +: weak, <5\% of tumor cells labeled; ++: moderate, $5-50 \%$ of cells labeled; +++ : intense, $>50 \%$ of cells labeled.
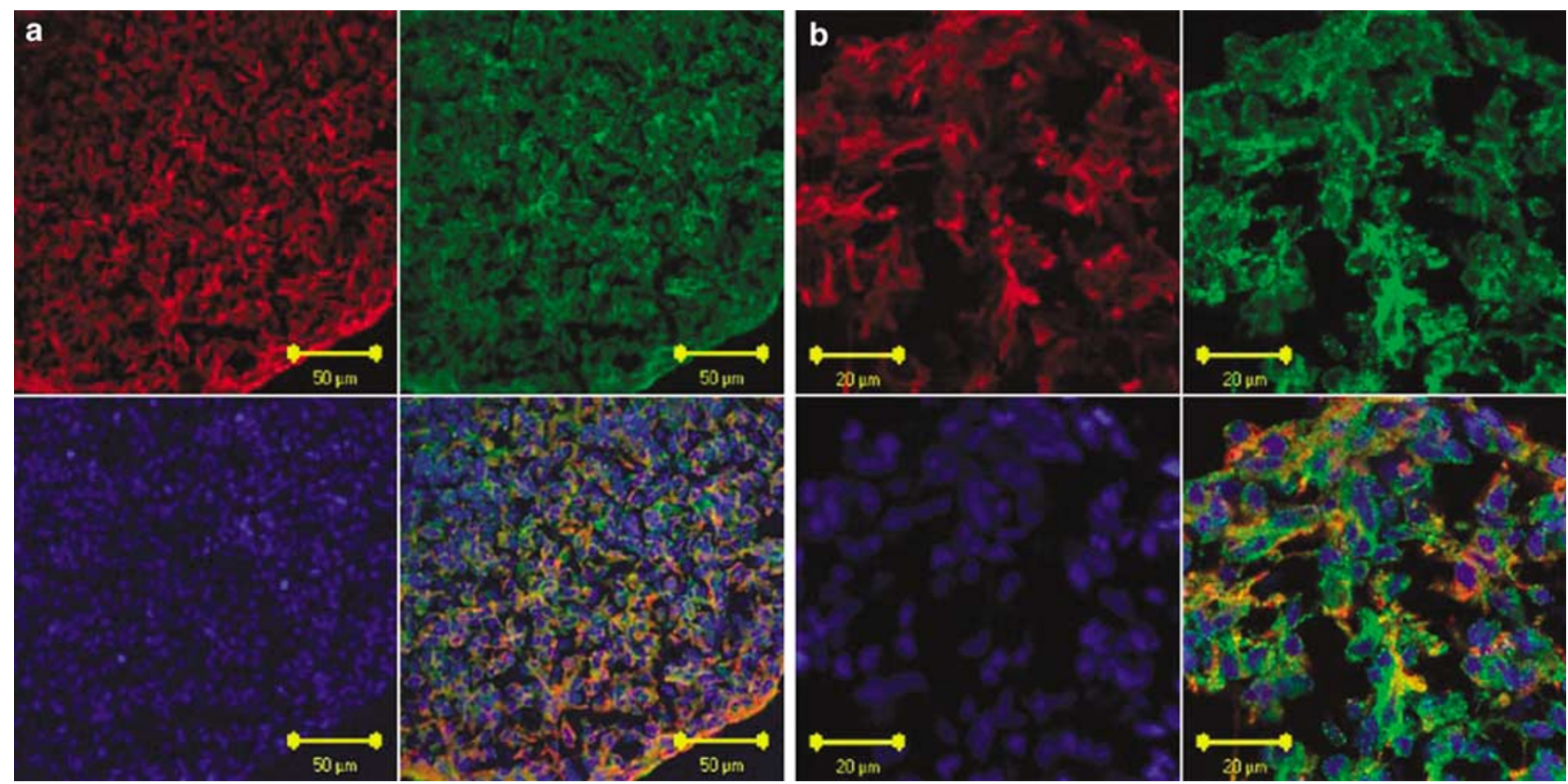

Figure 8 (a) Neurosphere, scale bar: $50 \mu \mathrm{m}$. (b) Neurosphere, scale bar: $20 \mu \mathrm{m}$, red: nestin, green: D2-40 blue: TO-PRO- $3^{\circledR}$ (nuclei staining) and the merged of these three images. The majority of human neural stem/progenitor cells within neurospheres were positively immunostained with D2-40 antibody on their cell surface as well as nestin antibody in the cytoplasm of them. 

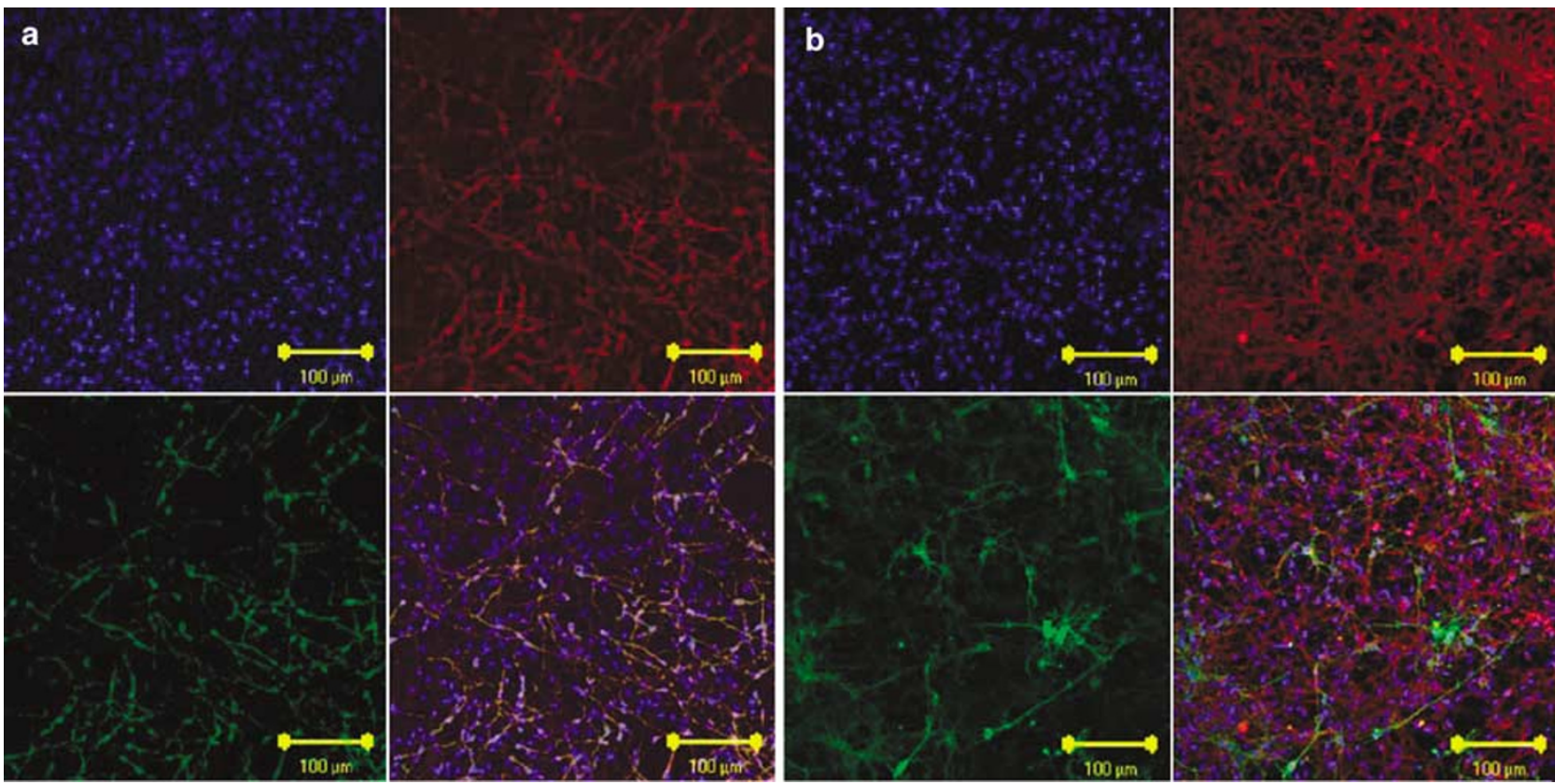

Figure 9 (a) Red: D2-40, green: PSA-NCAM, blue: TO-PRO- $3^{\circledR}$ (nuclei staining), the merged of these there images. Scale bar: $100 \mu \mathrm{m}$ (b) red: GFAP, green: D2-40, blue: TO-PRO- $3^{\circledR}$ (nuclei staining), the merged of these three images. Scale bar: $100 \mu \mathrm{m}$. After differentiation of human neural stem/progenitor cells, the distribution of the immunoreactivity of D2-40 was similar to that of PSA-NCAM, indicating expression on neuronal differentiated lineage (a). Only a small number of D2-40-positive cells seemed to share the positive immunoreactivity to GFAP (b).

(multidrug resistance 1), ${ }^{31}$ or ABCG2 (breast cancer resistance protein), ${ }^{32}$ that are generally expressed in endothelial cells in normal brains. ${ }^{33,34}$ It is also reported nestin is expressed in proliferative endothelial cells. ${ }^{35,36}$ Taken together, these previous findings and our present study suggest that both neural stem/progenitor cells and vascular and/or lymphatic endothelial cells share the same antigens and there might be some developmental analogies between them. Further investigation of the relationship between neural stem/progenitor cells and vascular and/or lymphatic endothelial cells will contribute greatly to our understanding of their biological properties. In addition, D2-40 antibody could be a candidate as a useful cell surface marker for isolation of human neural stem/progenitor cells and/or neuronal lineage cells in techniques such as fluorescence-activated cell sorting ${ }^{37-39}$ and will contribute to establishing new strategies for culturing human neural stem/progenitor cells intended for clinical applications.

\section{Acknowledgements}

This study was supported in part by the Project for the Realization of Regenerative Medicine, the research field for the Development of Stem Cell Therapy from the Ministry of Education, Culture, Sports, Science and Technology (MEXT) of Japan, the Cooperative Link of Unique Science and Technology for Economy Revitalization (CLUSTER) project from MEXT, Japan, and the Research on
Advanced Medical Technology, Health and Labour Sciences Research Grants, from the Ministry of Health, Labour and Welfare of Japan.

\section{References}

1 Bailey D, Baumal R, Law J, et al. Production of a monoclonal antibody specific for seminomas and dysgerminomas. Proc Natl Acad Sci USA 1986;83: 5291-5295.

2 Bailey D, Marks A, Stratis M, et al. Immunohistochemical staining of germ cell tumors and intratubular malignant germ cells of the testis using antibody to placental alkaline phosphatase and a monoclonal antiseminoma antibody. Mod Pathol 1991;4:167-171.

3 Marks A, Sutherland DR, Bailey D, et al. Characterization and distribution of an oncofetal antigen (M2A antigen) expressed on testicular germ cell tumours. Br J Cancer 1999;80:569-578.

4 Kahn HJ, Marks A. A new monoclonal antibody, D2-40, for detection of lymphatic invasion in primary tumors. Lab Invest 2002;82:1255-1257.

5 Kahn HJ, Bailey D, Marks A. Monoclonal antibody D240, a new marker of lymphatic endothelium, reacts with Kaposi's sarcoma and a subset of angiosarcomas. Mod Pathol 2002;15:434-440.

6 Franchi A, Gallo O, Massi D, et al. Tumor lymphangiogenesis in head and neck squamous cell carcinoma: a morphometric study with clinical correlations. Cancer 2004;101:973-978.

7 Dumoff KL, Chu C, Xu X, et al. Low D2-40 immunoreactivity correlates with lymphatic invasion and nodal metastasis in early-stage squamous cell carcinoma of the uterine cervix. Mod Pathol 2005;18:97-104. 
8 Choi WW, Lewis MM, Lawson D, et al. Angiogenic and lymphangiogenic microvessel density in breast carcinoma: correlation with clinicopathologic parameters and VEGF-family gene expression. Mod Pathol 2005; 18:143-152.

9 Debelenko LV, Perez-Atayde AR, Mulliken JB, et al. D2-40 immunohistochemical analysis of pediatric vascular tumors reveals positivity in kaposiform hemangioendothelioma. Mod Pathol 2005;18:14541460.

10 Chu AY, Litzky LA, Pasha TL, et al. Utility of D2-40, a novel mesothelial marker, in the diagnosis of malignant mesothelioma. Mod Pathol 2005;18: 105-110.

11 Ordonez NG. D2-40 and podoplanin are highly specific and sensitive immunohistochemical markers of epithelioid malignant mesothelioma. Hum Pathol 2005;36: 372-380.

12 Schacht V, Dadras SS, Johnson LA, et al. Up-regulation of the lymphatic marker podoplanin, a mucin-type transmembrane glycoprotein, in human squamous cell carcinomas and germ cell tumors. Am J Pathol 2005; 166:913-921.

13 Roy S, Chu A, Trojanowski JQ, et al. D2-40, a novel monoclonal antibody against the M2A antigen as a marker to distinguish hemangioblastomas from renal cell carcinomas. Acta Neuropathol (Berlin) 2005;109: 497-502.

14 Nakamura Y, Yamamoto M, Oda E, et al. Expression of tubulin beta II in neural stem/progenitor cells and radial fibers during human fetal brain development. Lab Invest 2003;83:479-489.

15 Nakamura Y, Yamamoto M, Oda E, et al. A novel marker for Purkinje cells, KIAA0864 protein. An analysis based on a monoclonal antibody HFB-16 in developing human cerebellum. J Histochem Cytochem 2005;53:423-430.

16 Reynolds BA, Tetzlaff W, Weiss SA. Multipotent EGFresponsive striatal embryonic progenitor cell produces neurons and astrocyte. J Neurosci 1992;12: 4565-4574.

17 Kanemura Y, Mori H, Kobayashi K, et al. Evaluation of in vitro proliferative activity of human fetal neural stem/progenitor cells using indirect measurements of viable cells based on cellular metabolic activity. J Neurosci Res 2002;69:869-879.

18 Seki T, Arai Y. Distribution and possible roles of a highly polysialylated neural cell adhesion molecule (NCAM-H) in the developing and adult central nervous system. Neurosci Res 1993;17:265290.

19 Walsh C, Cepko CL. Widespread dispersion of neuronal clones across functional regions of the cerebral cortex. Science 1992;255:434-440.

20 Lendahl U, Zimmerman LB, McKay RDG. CNS stem cells express a new class of intermediate filament protein. Cell 1990;60:585-595.

21 Tohyama T, Lee VM-y, Rorke LB, et al. Nestin expression in embryonic human neuroepithelium and in human neuroepithelial tumor cells. Lab Invest 1992;66:303-313.

22 Nixon RA, Shea TB. Dynamics of neuronal intermediate filaments: a developmental perspective. Cell Motil Cytoskel 1992;22:81-91.
23 Isumi H, Mizuguchi M, Takashima S. Differential development of the human cerebellar vermis: immunohistochemical and morphometrical evaluation. Brain Dev 1997;19:254-257.

24 Miyata M, Miyata H, Mikoshiba K, et al. Development of Purkinje cells in humans: an immunohistochemical study using a monoclonal antibody against the inositol, 4, 5-triphosphate type 1 receptor (IP3R1). Acta Neuropathol 1999;98:226-232.

25 Kato S, Hayashi H, Mikoshiba K, et al. Purkinje cells in olivocerebellar atrophy and granular cell-type cerebellar degeneration: an immunohistochemical study. Acta Neuropathol 1998;96:67-74.

26 Kato S, Ito $\mathrm{M}$, Ohame $\mathrm{E}$, et al. Immunohistochemical studies on cerebellar Purkinje cells of patients with Menke's kinky hair disease. Neuropathology 1993;13: 159-166.

27 Zecevic N, Rakic P. Differentiation of Purkinje cells and their relationship to other components of developing cerebellar cortex in man. J Comp Neurol 1976; 167:27-47.

28 Kanemura Y, Mori K, Sakakibara S, et al. Musashi1, an evolutionarily conserved neural RNA-binding protein, is a versatile marker of human glioma cells in determining their cellular origin, malignancy, and proliferative activity. Differentiation 2001;68:141-152.

29 Zakharov A, Papaiconomou C, Djenic J, et al. Lymphatic cerebrospinal fluid absorption pathways in neonatal sheep revealed by subarachnoid injection of Microfil. Neuropathol Appl Neurobiol 2003;29: $563-573$.

30 Wurmser AE, Nakashima K, Summers RG, et al. Cell fusion-independent differentiation of neural stem cells to the endothelial lineage. Nature 2004;430: 350-356.

31 Islam MO, Kanemura Y, Tajria J, et al. Characterization of ABC transporter ABCB1 expressed in human neural stem/progenitor cells. FEBS Lett 2005;579:3473-3480.

32 Islam MO, Kanemura Y, Tajria J, et al. Functional expression of ABCG2 transporter in human neural stem/progenitor cells. Neurosci Res 2005;52:75-82.

33 Sun H, Dai H, Shaik N, et al. Drug efflux transporters in the CNS. Adv Drug 2003;55:83-105.

34 Zhang W, Mojsilovic-Petrovic J, Andrade MF, et al. The expression and functional characterization of ABCG2 in brain endothelial cells and vessels. FASEB J 2003;17:2085-2087.

35 Mokry J, Cizkova D, Filip S, et al. Nestin expression by newly formed human blood vessels. Stem Cells Dev 2004;13:658-664.

36 Aihara M, Sugawara K, Torii S, et al. Angiogenic endothelium-specific nestin expression is enhanced by the first intron of the nestin gene. Lab Invest 2004; 84:1581-1592.

37 Keyoung HM, Roy NS, Benraiss A, et al. Highyield selection and extraction of two promoterdefined phenotypes of neural stem cells from the fetal human brain. Nat Biotechnol 2001;19:843-850.

38 Nunes MC, Roy NS, Keyoung HM, et al. Identification and isolation of multipotential neural progenitor cells from the subcortical white matter of the adult human brain. Nat Med 2003;9:439-447.

39 Maric D, Barker JL. Neural stem cells redefined: a FACS perspective. Mol Neurobiol 2004;30:49-76. 